\title{
A Priority Decision of Risk Using a Grey-Based Risk Decision Making Approach
}

\author{
KyoungJong Park \\ Gwangju University, Gwangju, Republic of Korea \\ kjpark@gwangju.ac.kr
}

\begin{abstract}
Because a supply chain consists of various enterprises, the sustainability of the chain should be granted, but a supply chain is being exposed to various risks. If the chain cannot respond effectively to the occurring risk, the chain could be damaged by the risk. The sustainability of an enterprise depends on effort that prevents a risk which does not occur and an effort that mitigates the impact of a risk which occurs. If a supply chain does not effectively control the preventable risks which give warning to a corporation and then the risks of the supply chain occur in practice. This paper, therefore, proposes a method which determines the priority of risks which encompass that a preventable risk which may occur and a resulting risk which occurs. The method obtains an opinion from the risk decision makers and proposes the risk priority using a grey-based risk decision making model to decrease the impact of risks in a supply chain.
\end{abstract}

Keywords: Sustainability, Supply chain, Grey-based risk decision making model, Priority

\section{Introduction}

If a supply chain is composed with many companies, the enterprises which are included in the supply chain maintain a cooperative system to obtain profit not only for the company but also to other companies. The corporations in a supply chain have to deal effectively with the matter which occurs in a company, among companies, or among supply chains. The matters which are called as risks are varied and the result appears very different by the strategy in a company, among companies, or among supply chains.

The risk of a supply chain is continuously increasing because of its uncertainty and complexity. A supply chain has a risk which means disruption and destruction and it gives consistent negative effects to the chain [1]. The problem of a supply chain is explained as risk, destruction, disruption, and etc. The activities to overcome it are explained as sustainability, resilience, and etc. [2-6].

Zsidisin \& Ritchie [7] defined a risk as "uncertainty based on a well grounded (quantitative) probability" and expressed it as Risk $=($ the probability that some event will occur) $\times$ (the consequences if it does occur). Also, the paper classified a risk in a supply chain into 5 categories, process and control which exist in a company, demand and supply which exist between a company and a supply chain, and environment which exists the outside of a supply chain. Chopra \& Sodhi [8] assorted a risk into system risk, forecast risk, intellectual property risk, procurement risk, receivables risk, inventory risk, and capacity risk. Tang \& Musa [9] classified it as material flow risk, financial flow risk, and information flow risk and evaluated it.Claypool et al. [10] proposed a model which is composed with two components, a Mixed Integer Programming (MIP) with time-tomarket risk, supplier reliability, and strategic exposure risk and a Simulation with supplier capacity risk and demand risk in a design for supply chain problem.

Because the vulnerability of a supply chain is easily exposed to other supply chains by various factors, the supply chain should effectively control the risk factors like 
disturbance, breakdown, and etc. Vulnerability is a construct which is consisting of two components, namely disturbance and the negative consequence of disturbance [11]. Even if a risk in a supply chain is continuously studied, the concept is still vague and ill-defined, and it is defined as the potential loss of a supply chain in terms of its target values of efficiency and effectiveness [12]. Also the study proposedquantitative risk measures as standard deviation, mean-variance approaches, value-at-risk (VaR), conditional-value-atrisk (CVaR), premiums, likelihood, the severity of adverse effects, and the extent of loss to measure a supply chain.

Fahimnia et al. [13] classified the area of risks into upstream SC risks (supply uncertainty and supplier evaluation issues), downstream SC risks (demand uncertainty issues), uncertainty in SC network design (modeling in supply chain network design and facility location), uncertainty in tactical/operational SC planning (modeling in tactical/operational supply chain planning), supply and demand forecasting analysis, uncertainty in inventory management/control (modeling in inventory management and process control), sustainability risks, and uncertainty in purchasing and retail sourcing.

The studies described, so far, categorized the sort of risks and focused their studies on how a risk influences on a supply chain. But, enough research has not carried in that a risk gives a different impact among companies and the result of a risk in a supply chain is different according to the response strategy of the supply chain. This study, therefore, proposes a method which determines a processing sequence of preventable risks and resulting risks, reflecting the possibility of a risk and the intensity of a risk. Basically, this paper uses a grey-based multi-criteria risk decision making method and follows a procedure which evaluates partially known risk information (grey values) and then proposes a risk response strategy.

In Section 1, this paper explains risk information and research purposes and a grey-based risk decision making approach is explained in Section 2. In Section 3, this study explains an experimental process of a grey-based risk decision making approach. Finally, the conclusions and future works are discussed in Section 4.

\section{A Grey-Based Risk Decision Making Model}

Li et al. [14] applied a grey-based decision-making approach for a supplier selection problem. Brito et al. [15] applied a grey-based ELECTRE approach for risk sorting of supply chains. Baskaran et al. [16] applied a grey approach for the sustainability evaluation of textile suppliers. Memon et al. [17] combined grey system theory and uncertainty theory and applied supplier selection. This study revises Park [18] and extends it to provide the detailed procedure and experimental results.

It is difficult to gather accurate information about occurrence time in a supply chain, occurrence frequency, and intensity of a risk and the supply chain cannot accurately measure the impact of a risk which influences on a company. This study, therefore, uses grey system theory to reflect the uncertainty and inconsistency of information, to prevent a risk in advance, and to minimize the result that a risk gives to a company. Grey system theory is a method which considers the condition of fuzziness and flexibility about insistent information in group decision making situations. That is, the method is one of the methods which solve complexity and uncertainty problems under discrete data and incomplete information.

A grey-based approach uses a grey number which lies between known and unknown information. The grey number is expressed by the boundaries of the grey number which lies between known and unknown information in Figure 1 [14-16]. 


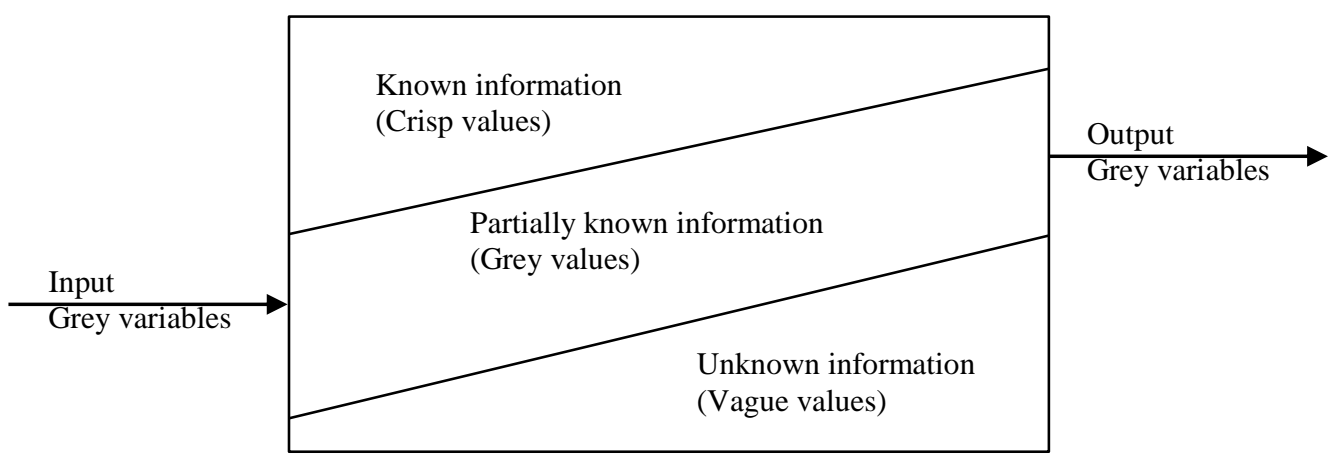

Figure 1. Boundaries of Grey Value

It assumes that $\mathrm{F}=\left\{F_{1}, F_{2}, \ldots, F_{m}\right\}$ is a discrete set of $\mathrm{m}$ possible alternatives and $\mathrm{M}=\left\{M_{1}, M_{2}, \ldots, M_{n}\right\}$ is a set of $\mathrm{n}$ attributes to apply a grey-based risk decision making approach. The attributes are additively independent. And $\otimes \mathrm{w}=\left\{\times w_{1}, \otimes w_{2}, \ldots, \otimes w_{n}\right\}$ is vector of attribute weights of $n$ attributes.

The steps of grey-based risk decision making model are summarized as follows.

Step 1: Gathering of decision makers' opinion about attributes and alternatives

This step gathers decision makers' decisions. First, it gathers decision maker's opinion about each attribute without considering alternatives. Next, it gathers the evaluation result of alternatives considering each attribute.

Step 2: Evaluation of grey weight of each attribute

In this step, the attribute decision is derived by aggregating the grey weights of an attribute from D decision makers calculated using Eq. (1).

$\mathrm{\otimes} w_{j}=\frac{1}{D}\left(\mathrm{\otimes} w_{j}^{1} \mathrm{\otimes} w_{j}^{2}+\cdots+\mathrm{\otimes} w_{j}^{d}\right), \mathrm{D}=1, \ldots, d$

where $\mathrm{x} w_{j}^{d}(\mathrm{j}=1, \ldots, \mathrm{n})$ is the attribute weight of $j$ th attribute with $d$ th decision maker and can be described by grey number $\otimes w_{j}^{d}=\left[w_{j}^{d}, \bar{w}_{j}^{d}\right]$. In this step, only the weight of attributes is calculated without considering the rating of alternatives.

Step 3: Evaluation of attribute rating value of each alternative

In this step, the attribute rating value of each alternative based on the preferences of $D$ decision makers with respect to $j$ th attribute can be calculated using Eq. (2)

$\mathrm{\otimes} E_{i j}=\frac{1}{D}\left[\otimes E_{i j}^{1}+\otimes E_{i j}^{2}+\cdots+\otimes E_{i j}^{d}\right]$

where $\otimes E_{i j}^{d}(\mathrm{i}=1, \ldots, \mathrm{m} ; \mathrm{j}=1, \ldots, \mathrm{n})$ is the attribute rating value of $i$ th alternative and $j$ th attribute with $d$ th decision maker.

Step 4: Establishment of grey weighted average and grey decision matrix

This step organizes the grey decision matrix using Eq. (2) with grey weighted average.

$\mathrm{E}=\left[\begin{array}{ccc}\mathrm{\otimes} E_{11} & \cdots & \mathrm{\otimes} E_{m 1} \\ \vdots & \ddots & \vdots \\ \otimes E_{1 n} & \cdots & \mathrm{\otimes} E_{m n}\end{array}\right]$

where $\otimes E_{i j}$ is linguistic variables based on the grey number. 
Step 5: Normalization of grey decision matrix

In this step, the normalization process maintains the property that the ranges of the normalized grey number belong to $[0,1]$. The normalized total grey decision matrix is shown in Eq. (4)

$E^{*}=\left[\begin{array}{ccc}\mathrm{x} E_{11}^{*} & \cdots & \mathrm{x} E_{m 1}^{*} \\ \vdots & \ddots & \vdots \\ \mathrm{x} E_{1 n}^{*} & \cdots & \mathrm{x} E_{m n}^{*}\end{array}\right]$

where for a maximization (benefit) attribute, $\circledast E_{i j}^{*}$ is expressed as $\circledast E_{i j}^{*}=$ $\left[\frac{E_{i j}}{E_{j}^{\max }}, \frac{\bar{E}_{i j}}{E_{j}^{\text {max }}}\right]$ and $E_{j}^{\text {max }}=\max _{1 \leq i \leq m}\left\{\bar{E}_{i j}\right\}$. And for a minimization (cost) attribute, $\otimes E_{i j}^{*}$ is expressed as $\otimes E_{i j}^{*}=\left[\frac{E_{j}^{\text {min }}}{\bar{E}_{i j}}, \frac{E_{j}^{\min }}{\underline{E}_{i j}}\right]$ and $E_{j}^{\min }=\min _{1 \leq i \leq m}\left\{\underline{E}_{i j}\right\}$.

Step 6: Establishment of the weighted and normalized grey decision matrix

In this step, the weighted and normalized grey decision matrix is established using Eq. (5) which considers the different weight of each attribute.

$$
N^{*}=\left[\begin{array}{ccc}
\otimes N_{11} & \cdots & \otimes N_{m 1} \\
\vdots & \ddots & \vdots \\
\otimes N_{1 n} & \cdots & \otimes N_{m n}
\end{array}\right]
$$

where $\otimes N_{i j}=\otimes E_{i j}^{*} \times \otimes w_{j}$. This step considers the different importance of each attribute.

Step 7: Making of the ideal alternative

This step sets the ideal alternative as referential alternative. For $m$ possible alternatives set, $\mathrm{F}=\left\{F_{1}, F_{2}, \ldots, F_{m}\right\} \quad, \quad$ the ideal referential alternative, $F^{\max }=\left\{\times \mathrm{N}_{1}^{\max }, \otimes \mathrm{N}_{2}^{\max }, \ldots, \otimes \mathrm{N}_{n}^{\max }\right\}$, can be established by Eq. (6).

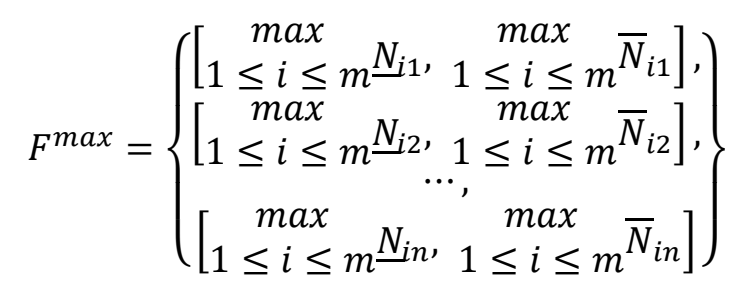

Step 8: Calculation of the grey possibility

This step calculates the grey possibility degree and compares alternatives set, $\mathrm{F}=$ $\left\{F_{1}, F_{2}, \ldots, F_{m}\right\}$, with ideal referential alternative $F^{\max }$ using Eq. (7).

$$
\mathrm{P}\left\{F_{i} \leq F_{\max }\right\}=\frac{1}{n} \sum_{j=1}^{n} P\left\{\otimes N_{i j} \leq N_{j}^{\max }\right\}
$$

Step 9: Ranking the order of alternatives

This step ranks the order of alternatives and selects the best alternative from among a set of feasible alternatives. If $\mathrm{P}\left\{F_{i} \leq F_{\text {max }}\right\}$ is smaller, the ranking order of $F_{i}$ is better.

\section{Experimental Process}

This study proposes a model which considers a preventable risk and a resulting risk which occurs when a preventable risk is not prevented by a company at the same time. 
The proposed method, therefore, should use a different approach which is not same to usual grey-based approach. Figure 2 explains the difference.

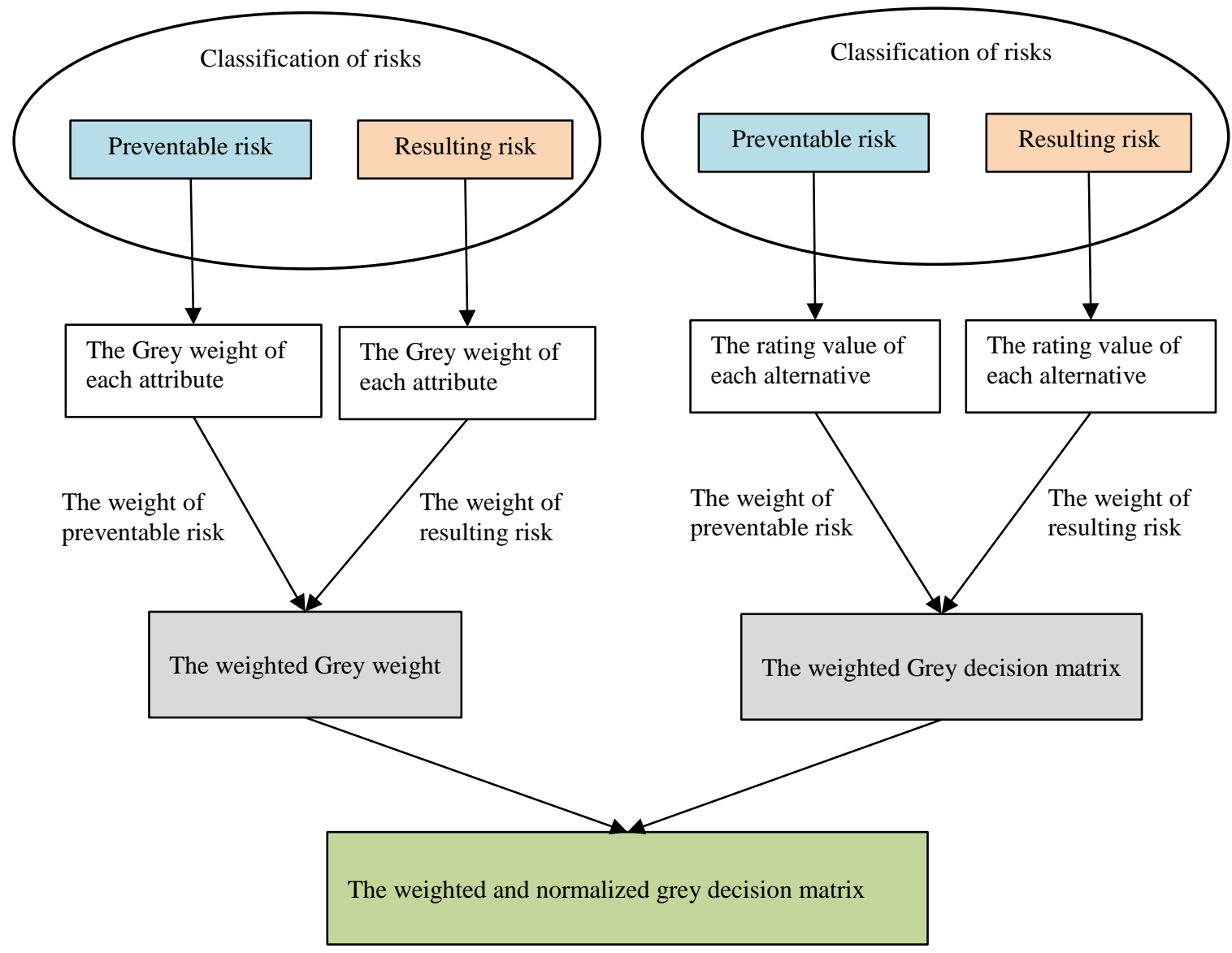

Figure 2. A Grey-Based Risk Decision Making Model

Because this paper considers a preventable risk and a resulting risk at the same time, the proposed method gives the weight of an attribute considering the opinion of the supply chain risk experts for a preventable risk and a resulting risk. In Figure 2, therefore, a preventable risk and a resulting risk for an attribute are evaluated through the grey value of an attribute and also a preventable risk and a resulting risk for an alternative are evaluated through the grey value of an alternative. Finally, they are integrated to the weighted and normalized grey decision matrix.

This study supposes that the weighted value of a preventable risk and a resulting risk is $0.3: 0.7$ in Step 2 of the grey-based risk decision making model. The weighted value is used equally to calculate the grey decision matrix and the averaged grey decision matrix for a preventable risk and a resulting risk in Step 3. Also, it is supposed that a supply chain has 4 tiers (Suppliers, Manufacutrers, Distributors, and Wholesalers) which are reflected into alternatives.

Table 1 represents the linguistic attribute weights in grey numbers and Table 2 shows the attribute rating value of alternatives in grey numbers. In Table 2, 'preventable risk Xresulting risk' is named as 'risk index', because it explains the degree of risk. 
Table 1. The Linguistic Attribute Weights in Grey Numbers

\begin{tabular}{|c|c|c|}
\hline \multicolumn{3}{|c|}{ The seriousness of attribute } \\
\hline Linguistic variables & \multicolumn{2}{|c|}{ grey numbers } \\
\hline Very Low (VL) & 0.0 & 0.1 \\
\hline Low (L) & 0.1 & 0.2 \\
\hline Medium Low (ML) & 0.2 & 0.3 \\
\hline Medium (M) & 0.3 & 0.6 \\
\hline Medium High (MH) & 0.6 & 0.7 \\
\hline High (H) & 0.7 & 0.8 \\
\hline Very High (VH) & 0.8 & 1.0 \\
\hline
\end{tabular}

Table 2. The Attribute Ratings Value of Alternatives in Grey Numbers

\begin{tabular}{|c|c|c|}
\hline \multicolumn{3}{|c|}{ The rating value of alternative } \\
\hline $\begin{array}{c}\text { Linguistic variables for risk index } \\
\text { (preventable risk } \times \text { resulting risk) }\end{array}$ & \multicolumn{2}{|c|}{ grey numbers } \\
\hline None (N) & 0 & 1 \\
\hline Pretty Rare (PR) & 1 & 2 \\
\hline Rare (R) & 2 & 3 \\
\hline Usual (U) & 3 & 6 \\
\hline Serious (S) & 6 & 7 \\
\hline Very Serious (VS) & 7 & 8 \\
\hline Uncontrollable (UC) & 8 & 10 \\
\hline
\end{tabular}

This study fulfills the algorithm of the grey-based risk decision making model using Table 1 and 2. Finally, the priority of risks is determined by the algorithm and a company in a supply chain can select a risk which is the worst risk. If a company prepares ahead the various strategies to avoid a preventable risk and a resulting risk and then the sustainability of a company will increase.

The risk experts of a supply chain are 4 members and this study supposes that the risk is to be considered into 8 (R1 R8) types. The risk experts' decision about the 8 types is shown in Table 3. The risk experts proposed that the effect of risks which effect on each tier (Suppliers, Manufacturers, Distributors, and Wholesalers) of a supply chain is shown in Table 4.

Table 3. The Risk Evaluation by Decision Makers

\begin{tabular}{|c|c|c|c|c|}
\hline \multirow{2}{*}{ Risk } & \multicolumn{4}{|c|}{ Decision makers } \\
\cline { 2 - 5 } & D1 & D2 & D3 & D4 \\
\hline R1 & VH & H & MH & H \\
\hline R2 & H & VH & VH & VH \\
\hline R3 & MH & H & ML & MH \\
\hline R4 & H & VH & H & VH \\
\hline R5 & L & VL & ML & L \\
\hline R6 & MH & MH & MH & M \\
\hline R7 & VL & VL & L & VL \\
\hline R8 & H & M & VH & M \\
\hline
\end{tabular}


Table 4. The Tier Evaluation Considering Risks by Decision Makers

\begin{tabular}{|c|c|c|c|c|c|c|c|c|c|c|c|c|c|c|c|c|}
\hline \multirow{2}{*}{ Attribute(Risk) } & \multicolumn{4}{|c|}{ A1(Suppliers) } & \multicolumn{4}{|c|}{ A2(Manufacturers) } & \multicolumn{4}{|c|}{ A3(Distributors) } & \multicolumn{4}{|c|}{ A4(Wholesalers) } \\
\hline & D1 & D2 & D3 & D4 & D1 & D2 & D3 & D4 & D1 & D2 & D3 & D4 & D1 & D2 & D3 & D4 \\
\hline $\mathrm{R} 1$ & $\mathrm{~N}$ & PR & $\mathrm{U}$ & $\mathrm{U}$ & $\mathrm{S}$ & VS & $\mathrm{N}$ & PR & PR & $\mathrm{N}$ & $\mathrm{R}$ & $\mathrm{R}$ & $\mathrm{N}$ & PR & $\mathrm{N}$ & $\mathrm{N}$ \\
\hline $\mathrm{R} 2$ & $\mathrm{PR}$ & $\mathrm{R}$ & $\mathrm{R}$ & $\mathrm{R}$ & $\mathrm{N}$ & $\mathrm{N}$ & PR & PR & $\mathrm{R}$ & $\mathrm{R}$ & VS & $\mathrm{N}$ & PR & $\mathrm{S}$ & $\mathrm{S}$ & $\mathrm{R}$ \\
\hline R3 & $\mathrm{S}$ & VS & UC & $\mathrm{UC}$ & $\mathrm{S}$ & $\mathrm{R}$ & $\mathrm{U}$ & $\mathrm{U}$ & $\mathrm{R}$ & $\mathrm{U}$ & $\mathrm{U}$ & $\mathrm{R}$ & $\mathrm{U}$ & $\mathrm{S}$ & $\mathrm{S}$ & $\mathrm{S}$ \\
\hline $\mathrm{R} 4$ & $\mathrm{PR}$ & $\mathrm{U}$ & $\mathrm{S}$ & $\mathrm{S}$ & $\mathrm{S}$ & $\mathrm{VS}$ & $\mathrm{UC}$ & $\mathrm{VS}$ & $\mathrm{UC}$ & VS & VS & $\mathrm{S}$ & VS & $\mathrm{VS}$ & $\mathrm{S}$ & $\mathrm{U}$ \\
\hline R5 & $\mathrm{S}$ & $\mathrm{S}$ & VS & $\mathrm{R}$ & $\mathrm{R}$ & VS & VS & UC & $\mathrm{R}$ & $\mathrm{S}$ & $\mathrm{S}$ & $\mathrm{S}$ & $\mathrm{U}$ & $\mathrm{U}$ & VS & $\mathrm{UC}$ \\
\hline R6 & $\mathrm{R}$ & $\mathrm{U}$ & $\mathrm{S}$ & $\mathrm{S}$ & PR & PR & $\mathrm{S}$ & $\mathrm{S}$ & $\mathrm{S}$ & VS & PR & PR & $\mathrm{N}$ & PR & $\mathrm{R}$ & PR \\
\hline $\mathrm{R} 7$ & VS & $\mathrm{U}$ & $\mathrm{R}$ & $\mathrm{R}$ & $\mathrm{S}$ & $\mathrm{S}$ & $\mathrm{U}$ & $\mathrm{U}$ & PR & PR & $\mathrm{U}$ & $\mathrm{U}$ & $\mathrm{R}$ & PR & PR & PR \\
\hline R8 & PR & PR & $\mathrm{N}$ & $\mathrm{N}$ & $\mathrm{R}$ & PR & PR & $\mathrm{R}$ & PR & $\mathrm{R}$ & $\mathrm{R}$ & $\mathrm{UC}$ & $\mathrm{S}$ & VS & $\mathrm{U}$ & $\mathrm{UC}$ \\
\hline
\end{tabular}

This paper applies a Grey-based risk decision making approach to find a tier which is most affected by the 8 risk types using Table 3 and 4 which are the evaluation result by the risk experts.

Step 1 calculates the Grey weight of each attribute (risk) which considers only each risk using Table 3 without considering the tires of a supply chain and then the result is shown in Table 5.

Table 5. The Grey Weight of Each Attribute (Risk)

\begin{tabular}{|c|c|c|}
\hline$\otimes \mathrm{W}$ & $\underline{x}$ & $\bar{x}$ \\
\hline $\mathrm{w} 1$ & 0.700 & 0.825 \\
\hline $\mathrm{w} 2$ & 0.775 & 0.950 \\
\hline $\mathrm{w} 3$ & 0.525 & 0.625 \\
\hline $\mathrm{w} 4$ & 0.750 & 0.900 \\
\hline $\mathrm{w} 5$ & 0.100 & 0.200 \\
\hline $\mathrm{w} 6$ & 0.525 & 0.675 \\
\hline $\mathrm{w} 7$ & 0.025 & 0.125 \\
\hline $\mathrm{w} 8$ & 0.525 & 0.750 \\
\hline
\end{tabular}

Step 2 and 3 calculate the Grey decision matrix which considers each risk using Table 4 considering the tiers of a supply chain and then the result is shown in Table 6 .

Table 6. The Grey Decision Matrix

\begin{tabular}{|c|c|c|c|c|c|c|c|c|}
\hline $\begin{array}{c}\text { Alternative } \\
\text { Risk }\end{array}$ & \multicolumn{2}{l|}{ A1(Suppliers) } & \multicolumn{2}{l|}{ A2(Manufacturers) } & \multicolumn{2}{l|}{ A3(Distributors) } & \multicolumn{2}{l|}{ A4(Wholesalers) } \\
\hline R1 & 1.750 & 3.750 & 3.500 & 4.500 & 1.250 & 2.250 & 0.250 & 1.250 \\
\hline R2 & 1.750 & 2.750 & 0.500 & 1.500 & 2.750 & 3.750 & 3.750 & 4.750 \\
\hline R3 & 7.250 & 8.750 & 3.500 & 5.500 & 2.500 & 4.500 & 5.250 & 6.750 \\
\hline R4 & 4.000 & 5.500 & 7.000 & 8.250 & 7.000 & 8.250 & 5.750 & 7.250 \\
\hline R5 & 5.250 & 6.250 & 6.000 & 7.250 & 5.000 & 6.000 & 5.250 & 7.500 \\
\hline R6 & 4.250 & 5.750 & 3.500 & 4.500 & 3.750 & 4.750 & 1.000 & 2.000 \\
\hline R7 & 3.500 & 5.000 & 4.500 & 6.500 & 2.000 & 4.000 & 1.250 & 2.250 \\
\hline R8 & 0.500 & 1.500 & 1.500 & 2.500 & 3.250 & 4.500 & 6.000 & 7.750 \\
\hline
\end{tabular}

Step 4 normalizes the Grey decision matrix of Table 6 to not to underestimate other risks by the specific effect of a risk and the result is shown in Table 7 . 
Table 7. The Normalization of the Grey Decision Matrix

\begin{tabular}{|c|c|c|c|c|c|c|c|r|}
\hline Risk & \multicolumn{3}{|l|}{ A1(Suppliers) } & \multicolumn{2}{|c|}{ A2(Manufacturers) } & \multicolumn{2}{c|}{ A3(Distributors) } & \multicolumn{2}{c|}{ A4(Wholesalers) } \\
\hline R1 & 0.389 & 0.833 & 0.778 & 1.000 & 0.278 & 0.500 & 0.056 & 0.278 \\
\hline R2 & 0.368 & 0.579 & 0.105 & 0.316 & 0.579 & 0.789 & 0.789 & 1.000 \\
\hline R3 & 0.829 & 1.000 & 0.400 & 0.629 & 0.286 & 0.514 & 0.600 & 0.771 \\
\hline R4 & 0.485 & 0.667 & 0.848 & 1.000 & 0.848 & 1.000 & 0.697 & 0.879 \\
\hline R5 & 0.700 & 0.833 & 0.800 & 0.967 & 0.667 & 0.800 & 0.700 & 1.000 \\
\hline R6 & 0.739 & 1.000 & 0.609 & 0.783 & 0.652 & 0.826 & 0.174 & 0.348 \\
\hline R7 & 0.538 & 0.769 & 0.692 & 1.000 & 0.308 & 0.615 & 0.192 & 0.346 \\
\hline R8 & 0.065 & 0.194 & 0.194 & 0.323 & 0.419 & 0.581 & 0.774 & 1.000 \\
\hline
\end{tabular}

Step 5 calculates the weighted and normalized Grey decision matrix which has the result of each risk considering the tiers of a supply chain by the risk experts and the result is shown in Table 8.

\section{Table 8. The Calculation of the Weighted and Normalized Grey Decision} Matrix

\begin{tabular}{|c|c|c|c|c|c|c|c|c|}
\hline Risk & \multicolumn{3}{|l|}{ A1(Suppliers) } & \multicolumn{2}{|c|}{ A2(Manufacturers) } & \multicolumn{2}{c|}{ A3(Distributors) } & \multicolumn{2}{c|}{ A4(Wholesalers) } \\
\hline R1 & 0.272 & 0.688 & 0.544 & 0.825 & 0.194 & 0.413 & 0.039 & 0.229 \\
\hline R2 & 0.286 & 0.550 & 0.082 & 0.300 & 0.449 & 0.750 & 0.612 & 0.950 \\
\hline R3 & 0.435 & 0.625 & 0.210 & 0.393 & 0.150 & 0.321 & 0.315 & 0.482 \\
\hline R4 & 0.364 & 0.600 & 0.636 & 0.900 & 0.636 & 0.900 & 0.523 & 0.791 \\
\hline R5 & 0.070 & 0.167 & 0.080 & 0.193 & 0.067 & 0.160 & 0.070 & 0.200 \\
\hline R6 & 0.388 & 0.675 & 0.320 & 0.528 & 0.342 & 0.558 & 0.091 & 0.235 \\
\hline R7 & 0.013 & 0.096 & 0.017 & 0.125 & 0.008 & 0.077 & 0.005 & 0.043 \\
\hline R8 & 0.034 & 0.145 & 0.102 & 0.242 & 0.220 & 0.435 & 0.406 & 0.750 \\
\hline
\end{tabular}

Step 6 makes the ideal alternative (tier) and Step 7 calculates the Grey possibility degree between and the compared alternatives of all alternatives. The result is shown in Table 9.

Table 9. The Grey Possibility Degree between the Compared Alternatives

\begin{tabular}{|c|c|c|c|c|}
\hline $\begin{array}{r}\text { Alternativ } \\
\text { Risk }\end{array}$ & $\begin{array}{c}\text { A1(Suppliers } \\
\text { ) }\end{array}$ & $\begin{array}{c}\text { A2(Manufacturers } \\
\text { ) }\end{array}$ & $\begin{array}{c}\text { A3(Distributors } \\
\text { ) }\end{array}$ & $\begin{array}{c}\text { A4(Wholesalers } \\
\text { ) }\end{array}$ \\
\hline R1 & 0.794 & 0.500 & 1.000 & 1.000 \\
\hline R2 & 1.000 & 1.000 & 0.784 & 0.500 \\
\hline R3 & 0.500 & 1.000 & 1.000 & 0.868 \\
\hline R4 & 1.000 & 0.500 & 0.500 & 0.709 \\
\hline R5 & 0.587 & 0.500 & 0.613 & 0.507 \\
\hline R6 & 0.500 & 0.717 & 0.662 & 1.000 \\
\hline R7 & 0.586 & 0.500 & 0.663 & 0.822 \\
\hline R8 & 1.000 & 1.000 & 0.948 & 0.500 \\
\hline Average & 0.746 & 0.715 & 0.771 & 0.738 \\
\hline
\end{tabular}

Step 8 ranks the order of tier alternatives which is most at the risks and then the sequence is $\mathrm{A} 2>\mathrm{A} 4>\mathrm{A} 1>\mathrm{A} 3$. That is, the result proposes that Manufacturers tier is most 
at the risks and the next, Wholesalers tier is weak. On the contrary to this, the result shows that Distributors tier is the most resistant about the risks.

\section{Conclusions and Future Works}

The accurate decision for the risk is not easily made because information for a risk which occurs in a supply chain is vague and fuzzy. Also, if the prevention strategies for a risk in a supply chain are effectively established in advance, a risk does not occur. Even if a risk occurs, the impact of a risk may be less than the prevention strategies which are not established. This study, therefore, proposed a grey-based risk decision making model considering a preventable risk and a resulting risk at the same time to find a risk factor which has the most risk possibility and to avoid the impact of a risk.

If a company accepts the warning of a preventable risk, which budget needs more to manufacture a product and sells it in a supply chain and then the firm establishes the procurement of budget or the strategy of budget savings, the risk is removed from the supply chain and the manufacturing and selling process works normally. But, a corporation cannot secure budget, there occurs many problems in the purchasing of raw materials and facilities, facilities maintenance, the payment of wage, and etc. Finally, the supply chain is affected by the problems and then many companies of the chain cost businesses money in lost productivity. A supply chain needs 2 steps to decrease a risk. First, the supply chain should make a strategy which faithfully responses for a preventable risk. Next, the system should make a risk mitigation strategy to mitigate the impact of a resulting risk which occurs because it did not prevent a preventable risk in advance. Therefore, a preventable risk and a resulting risk must be considered in a supply chain at the same time to increase the sustainability of the chain.

This study classified risks into preventable risks and resulting risks and then evaluated its impact and made a priority. But its classification should conduct more detail. In future works, the criteria for classification technique needs to classify them for preventable risks and resulting risks.

\section{Acknowledgments}

This study was conducted by research funds from Gwangju University in 2016.

\section{References}

[1] A. Nair and J. M. Vidal, "Supply Network Topology and Robustness against Disruptions- An Investigation Using Multi-agent Model", International Journal of Prod. Res, vol. 49, no. 5, (2011), pp.1391-1404.

[2] S. Derissen, M. F. Quaas and S. Baumgärtner, "The Relationship between Resilience and Sustainability of Ecological-Economic Systems", Ecol. Econ, vol. 70, no. 6, (2011), pp. 1121-1128.

[3] S. I. Mari, Y. H. Lee and M. S. Memon, "Sustainable and Resilient Supply Chain Network Design Under Disruption Risks", Sustainability, vol. 6, no. 10, (2014), pp. 6666-6686.

[4] K. J. Park, "Risk Evaluation of a Supply Chain Using Agent-Based Model and System Dynamics", J. Korean Soc. Supply Chain Manag, vol. 14, no. 2, (2014), pp. 45-50.

[5] K. J. Park and G. Kyung, "Optimization of Total Inventory Cost and Order Fill Rate in a Supply Chain Using PSO”, International Journal of Adv. Manuf. Tech, vol. 70, no. 9-12, (2014), pp. 1533-1541.

[6] L. Qi, Z. M. Shen and L. V. Snyder, "The Effect of Supply Disruptions on Supply Chain Design Decisions", Transport. Sci, vol. 44, no. 2, (2010), pp.274-289.

[7] G. A. Zsidisin and B. Ritchie, "Supply Chain Risk, Springer", New York, (2008).

[8] S. Chopra and M. S. Sodhi, "Managing Risk to Avoid Supply-Chain Breakdown", MIT Sloan Manage. Rev, vol. 46, no. 1, (2004), pp. 53-61.

[9] O. Tang and S. N. Musa, "Identifying Risk Issues and Research Advancements in Supply Chain Risk Management”, International Journal of Prod. Econ, vol. 133, no. 1, (2011), pp. 25-34.

[10] E. Claypool, B. A. Norman and K. L. Needy, "Modeling risk in a Design for Supply Chain problem", Comput. Ind. Eng, vol .78, (2014), pp. 44-54.

[11] G. A. Svensson, "Conceptual Frame Work for the Analysis of Vulnerability in Supply Chains", International Journal of Phys. Distr. Log, vol. 30, no. 9, (2000), pp. 731-50. 
[12] I. Heckmann, T. Comes and S. Nickel, "A Critical Review on Supply Chain Risk-Definition, Measure and Modeling", Omega, vol. 52, (2015), pp. 119-132.

[13] B. Fahimnia, C. S. Tang, H. Davarzani and J. Sarkis, "Quantitative Models for Managing Supply Chain Risks: A Review”, Eur. Journal of Oper. Res, vol. 247, no. 1, (2015), pp. 1-15.

[14] G. D. Li, D. Yamaguchi and M. Nagai, "A Grey-Based Decision-Making Approach to the Supplier Selection Problem”, Math. Comput. Model, vol. 46, no. 3-4, (2007), pp. 573-581.

[15] A. J. Brito, A. T. Almeida and C. M. M. Mota, "A Multi Criteria Model for Risk Sorting of Natural Gas Pipelines Based on ELECTRE TRI Integrating Utility Theory”, Eur. J. Oper. Res, vol. 200, no. 3, (2010), pp. 812-821.

[16] V. Baskaran, S. Nachiappan and S. Rahman, "Indian Textile Suppliers' Sustainability Evaluation Using the Grey Approach", Int. J. Prod. Econ, vol. 135, no. 2, (2012), pp. 647-658.

[17] M. S. Memon, Y. H. Lee and S. I. Mari, "Group Multi-Criteria Supplier Selection Using Combined Grey Systems Theory and Uncertainty Theory”, Expert Syst. Appl, vol. 42, no. 21, (2015), pp. 79517959.

[18] K. J. Park, "A Grey-Based Risk Decision Making Approach to Prevention and Mitigation Strategy", Proceedings of Advanced Science and Technology Letters (Business 2015), Jeju, Korea, (2015) December 14-16, pp. 146-150.

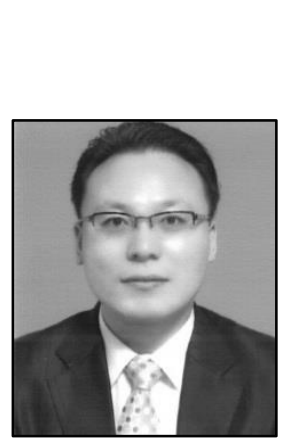

\begin{abstract}
Authors
KyoungJong Park is a Professor in the Department of Business Administration, Gwangju University, Korea. He received his B.Sc., M.Sc., and Ph.D. from the Department of Industrial Engineering, Hanyang University, Korea in 1992, 1994, and 1998. He spent a sabbatical year at Pennsylvania State University, 2010-2011. His research interests are Fuzzy Information, Evolutionary Algorithm, Simulation Optimization, and Service Supply Chain Management.
\end{abstract}

